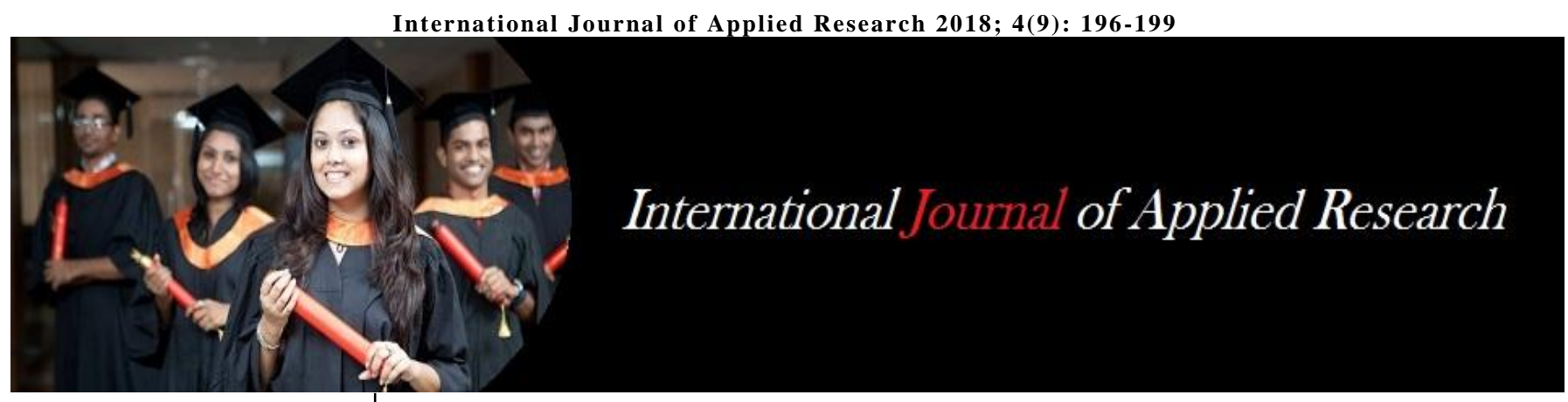

ISSN Print: 2394-7500

ISSN Online: 2394-5869

Impact Factor: 5.2

IJAR 2018; 4(9): 196-199

www.allresearchjournal.com

Received: 28-07-2018

Accepted: 30-08-2018

Kumari S

Senior Resident, AIIMS,

Patna, Bihar, India

Verma M

Junior Resident, RGICR, New

Delhi, India

Narayan RK

Senior Resident, AIIMS,

Patna, Bihar, India
Correspondence

Kumari S

Senior Resident, AIIMS,

Patna, Bihar, India

\section{Linear dimensions of clavicle in East Indian population of Bihar}

\author{
Kumari S, Verma M and Narayan RK
}

http://dx.doi.org/10.22271/allresearch.2018.v4.19c.10

\begin{abstract}
The clavicle is a sigmoid-shaped bone that is easily visible in thin people and is palpable in all except the morbidly obese. The atypical asymmetric pattern and varied diaphyseal breadths are results of patterns of an individual, mechanical behaviour and unique developmental pathway of clavicle. The varied diaphyseal breadths are being more sensitive to the effects of loadings than the lengths. This study was conducted in the Department of Anatomy, AIIMS, Patna. The sample size was of 30 adult clavicles. Bones showing obvious pathological deformities were excluded from the study. Factors such as mechanical load, pressure and tension created by muscular attachments, and genetic endowments might be responsible for such asymmetries not only in various metric traits of clavicle but also among the non-metric traits of both side human clavicles. The fact of lesser intake of calcium in the form of milk and milk products by the East Indian population and this may have led to decreased thickness of the bone and hence lesser midclavicular circumference.
\end{abstract}

Keywords: Clavicle, mechanical behaviour, genetic endowments, asymmetries, midclavicular circumference

\section{Introduction}

The clavicle is a sigmoid-shaped bone that is easily visible in thin people and is palpable in all except the morbidly obese. Its medial two-thirds are rounded and convex anteriorly and the lateral third is flat and concave anteriorly. Before birth i. e. in early foetal life, much of the adult morphology of human clavicle (a double-curved S-shaped outline) is attained ${ }^{[1]}$.

The atypical asymmetric pattern and varied diaphyseal breadths are results of patterns of an individual, mechanical behaviour and unique developmental pathway of clavicle. The varied diaphyseal breadths are being more sensitive to the effects of loadings than the lengths. Clavicle has been found thicker and more curved in manual workers. Significant shortening or asymmetry of clavicle in skeletally mature adults can affect clinical/surgical treatment strategies. Properly explained data of anatomical and biomechanical features (like dimensions, diameters, robusticity) of this bone helps in understanding and preventing the pre- and post-operative complications of clavicle fixations. Increased rates of non-unions and more demands for use of nail and plate fixative devices for treating clavicular fractures have necessitated some extensive studies based on examination of its anatomical and morphological features ${ }^{[2,3]}$.

The present study was conducted on the clavicles retrieved from Eastern India population with the

Objectives

1. To estimate mean value of anatomical dimensions of clavicle.

2. To highlight inter-disciplinary significance, if any, of various morphometric and nonmetric features of clavicle.

\section{Materials \& Methods}

This study was conducted in the Department of Anatomy, AIIMS, and Patna. The sample size was of 30 adult clavicles. Bones showing obvious pathological deformities were excluded from the study.

Parsons ${ }^{[6]}$ method was followed to measure the following: 
(i) Clavicular length (CL): It is measured as the maximum distance between the outermost tips of the sternal and acromial ends of clavicle placed on an osteometric board (ignoring curves of the bone) accurate to within $0.01 \mathrm{~cm}^{[4,5]}$.

(ii) Articular Length of Clavicle (AL): It is the straight distance between the mid-points of the sternal and acromial articular ends of clavicle measured with the help of a spreading caliper with pointed ends, accurate to within 0.01 $\mathrm{cm}$ as per the technique used by Parsons ${ }^{[6]}$.

(iii) Mid-point Circumference (CC): The midpoint of clavicular shaft is marked between acromial and sternal ends of clavicle placed in anatomical position on the osteometric board and circumference is measured at this point with a strip of graph paper marked in centimetres, accurate to be within $0.01 \mathrm{~cm}$

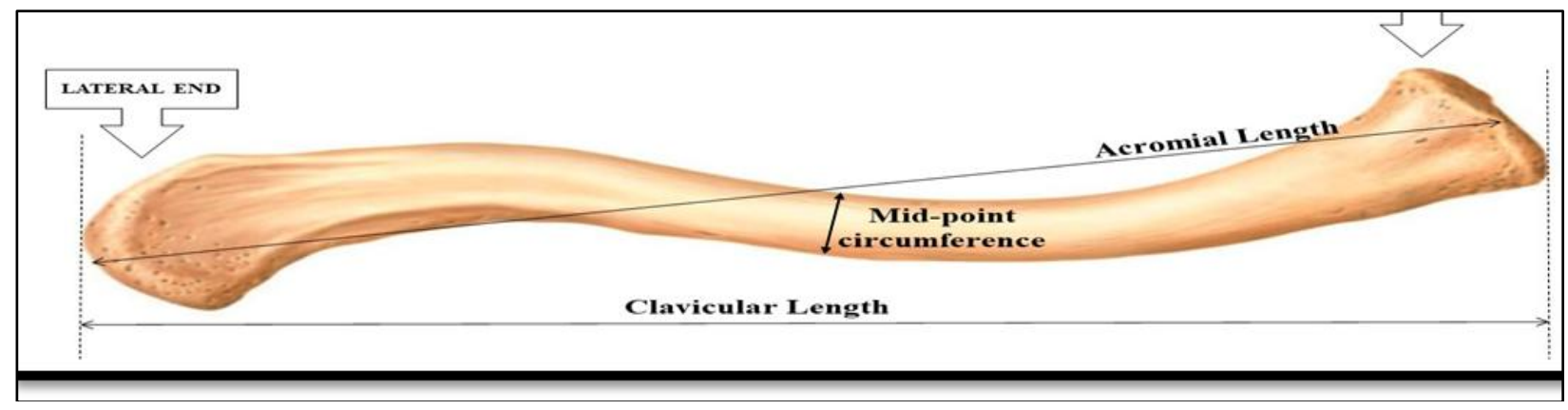

Fig 1

\section{Results}

Table 1: Showing mean values of Clavicular length (in $\mathrm{mm}$ ) on both sides

\begin{tabular}{|c|c|c|}
\hline \multirow{2}{*}{} & \multicolumn{2}{|c|}{ Clavicular length (in mm) } \\
\cline { 2 - 3 } & Right & Left \\
\hline Mean & 147.36 & 152.63 \\
\hline Std. Dev & 15.34 & 13.60 \\
\hline p value & \multicolumn{2}{|c|}{0.51} \\
\hline
\end{tabular}

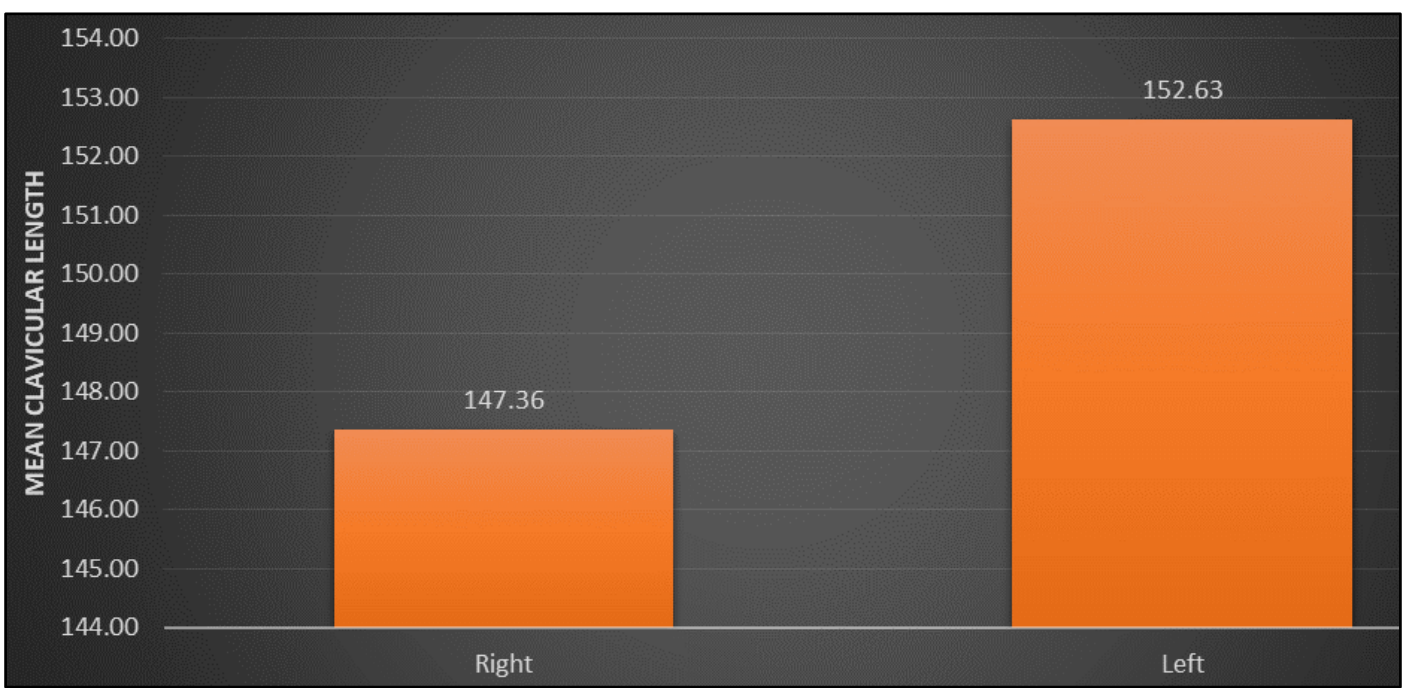

Graph 1: Showing bilateral variation in clavicular length

Table 1, shows the mean values of clavicular length as 14.69 $\mathrm{cm}$ in left and $15.21 \mathrm{~cm}$ on the right side with standard deviation of $1.53 \mathrm{~cm}$ and $1.37 \mathrm{~cm}$ respectively. So, on the right side the clavicular length was more as compared to the left side of East Indian population (Graph 1).

Table 2: Showing mean values of Acromial length (in $\mathrm{mm}$ ) on both sides

\begin{tabular}{|c|c|c|}
\hline \multirow{2}{*}{} & \multicolumn{2}{|c|}{ Acromial length (in mm) } \\
\cline { 2 - 3 } & Right & Left \\
\hline Mean & 144.70 & 148.99 \\
\hline Std. Dev & 16.45 & 13.99 \\
\hline p value & \multicolumn{2}{|c|}{0.52} \\
\hline
\end{tabular}




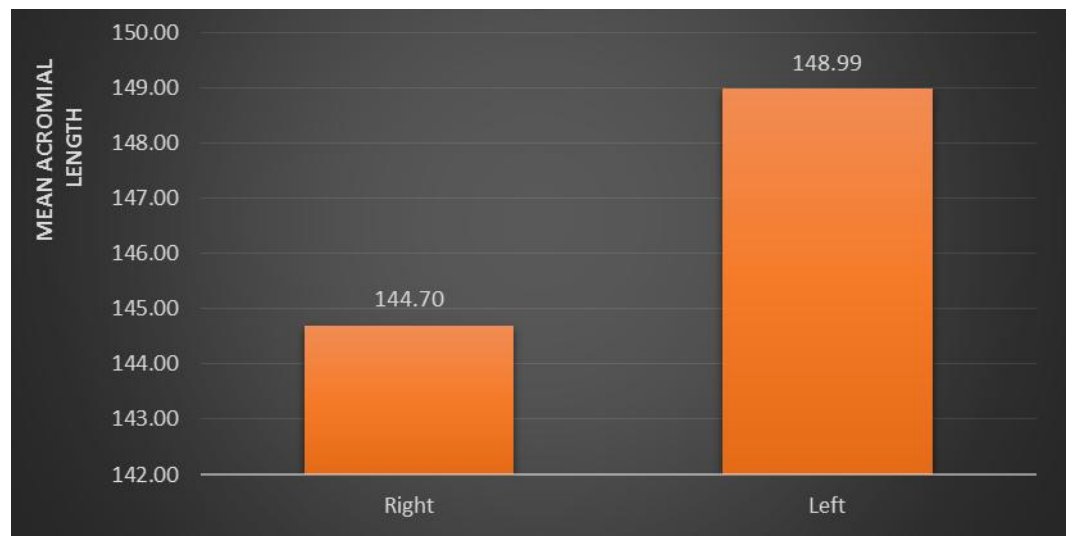

Graph 2: Showing bilateral variation in acromial length

As shown in table 2 and Graph 2, the mean values of articular length on the right side was $14.34 \mathrm{~cm}$ and that on the left was slightly higher being 14.86 with standard deviation of $1.58 \mathrm{~cm}$ and $1.41 \mathrm{~cm}$.

Hence both the articular and clavicular lengths were higher on the left side than the right.
Table 3: Showing mean values of Mid-Point Circumference (in $\mathrm{mm}$ ) on both sides

\begin{tabular}{|c|c|c|}
\hline \multirow{2}{*}{} & \multicolumn{2}{|c|}{ Mid - point circumference, CC (in mm) } \\
\cline { 2 - 3 } & Right & Left \\
\hline Mean & 35.53 & 32.25 \\
\hline Std. Dev & 4.47 & 3.44 \\
\hline p value & \multicolumn{2}{|c|}{0.13} \\
\hline
\end{tabular}

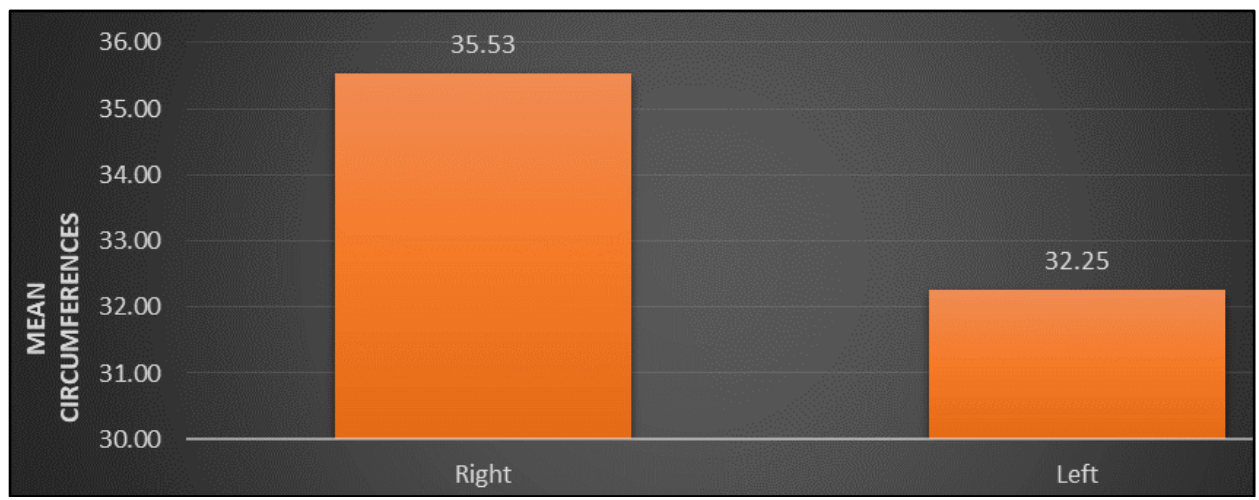

Graph 3: Showing bilateral variation in Mid-Point Circumference of Clavicle

The mid-point circumference of clavicle was higher on the right side than the left (graph3) with values of $3.54 \mathrm{~cm}$ and $3.2 \mathrm{~cm}$ respectively (table 3 ).

All the three dimensions were statistically insignificant with p-value $>0.05$.

\section{Discussion}

Table 4: Comparison of mean length of clavicle reported in different populations.

\begin{tabular}{|c|c|c|c|c|}
\hline \multirow[t]{2}{*}{ Authors } & \multicolumn{2}{|c|}{ Right (in mm) } & \multicolumn{2}{|c|}{ Left (in mm) } \\
\hline & Males & Females & Males & Females \\
\hline Parsons ${ }^{[6]}$ (English) & 152 & 138 & 154 & 139 \\
\hline Singh $^{[11]}$ (USA Whites) & 151.40 & 133.68 & 153.37 & 134.84 \\
\hline Terry ${ }^{[12]}$ (USA Negroes) & $153.30 \pm 0.83$ & $140.98 \pm 0.76$ & $155.86 \pm 0.92$ & $141.78 \pm 0.03$ \\
\hline Singh ${ }^{[11]}$ (USA Negroes) & 155.72 & 137.60 & 157.32 & 140.80 \\
\hline Olivier $^{13}($ French $)$ & 154.20 & 137.90 & 155 & 138.70 \\
\hline Patel et al ${ }^{[14]}$ (Western India) & $141.85 \pm 9.5$ & $125.9 \pm 7.4$ & $142.3 \pm 8.98$ & $126.88 \pm 8.86$ \\
\hline Sayee et al ${ }^{[15]}$ (South India) & $137 \pm 9.0$ & $123.9 \pm 8.0$ & $142.3 \pm 8.98$ & $128.20 \pm 9.0$ \\
\hline Sehrawat \& Pathak ${ }^{[2]}$ (North India) & $148.52 \pm 8.88$ & $135.22 \pm 8.27$ & $151.87 \pm 8.98$ & $138.22 \pm 8.3$ \\
\hline Kaur et al ${ }^{[3]}$ (North India) & $135.20 \pm 9.24$ & $130.51 \pm 11.51$ & $137.29 \pm 9.20$ & $132.67 \pm 11.51$ \\
\hline Present Study & \multicolumn{2}{|c|}{$147.36 \pm 15.34$} & \multicolumn{2}{|c|}{$152.63 \pm 13.6$} \\
\hline
\end{tabular}

Clavicular length has been the most discussed parameter among various reported ones. The left human clavicle is generally found longer than the right one due to the differences laid down in early intra-uterine life of an individual ${ }^{[7,8]}$. King et al reported that, left clavicle was longer than the right one in $65 \%$ male $(4.55 \mathrm{~mm})$ and $67 \%$ female $(3.14 \mathrm{~mm})$ cases ${ }^{[9]}$. Cunningham et al., found that $28 \%$ clavicles were dimensionally (length-wise) asymmetric (up to $5 \mathrm{~mm}$ side differences), but $7 \%$ clavicles had clinically significant asymmetry with more than $10 \mathrm{~mm}$ side differences that could affect treatment decisions ${ }^{[10]}$. Factors such as mechanical load, pressure and tension created by 
muscular attachments, and genetic endowments might be responsible for such asymmetries not only in various metric traits of clavicle but also among the non-metric traits of both side human clavicles. In present study, mean clavicular length results were lesser than the Western population but higher than other Indian population.

Table 5: Comparison of mid-Clavicular circumference of clavicle as reported by various authors

\begin{tabular}{|c|c|c|c|c|}
\hline \multirow[t]{2}{*}{ Authors } & \multicolumn{2}{|c|}{ Right (in mm) } & \multicolumn{2}{|c|}{ Left (in mm) } \\
\hline & Males & Females & Males & Females \\
\hline Jit \& Singh ${ }^{[3]}$ (Amritsar) & $36.17 \pm 3.02$ & $29.69 \pm 1.74$ & $35.7 \pm 3.16$ & $29.51 \pm 1.97$ \\
\hline Singh \& Gangrade ${ }^{[3]}$ (Varanasi) & $35.09 \pm 3.17$ & $28.52 \pm 2.37$ & $34.64 \pm 3.17$ & $28 \pm 2.22$ \\
\hline Jit \& Sahni ${ }^{3}$ (Chandigarh) & $36.2 \pm 3.50$ & $30.4 \pm 2.70$ & $35.9 \pm 2.70$ & $30 \pm 2.80$ \\
\hline Kaur et al ${ }^{[3]}$ (Patiala) & $36.97 \pm 3.62$ & $30.83 \pm 2.89$ & $36.91 \pm 3.57$ & $30.69 \pm 2.98$ \\
\hline Patel et al (Gujarat) & $37.1 \pm 2.99$ & $30.15 \pm 2.46$ & $36.44 \pm 3.46$ & $30.16 \pm 2.72$ \\
\hline Sehrawat \& Pathak (North India) & $38.52 \pm 3.28$ & $32.66 \pm 2.57$ & $37.24 \pm 3.38$ & $31.76 \pm 2.70$ \\
\hline Kaur et ${ }{ }^{[3]}$ (North India) & $39.3 \pm 0.42$ & $39.2 \pm 0.75$ & $38.8 \pm 0.37$ & $38.8 \pm 0.69$ \\
\hline Present Study & \multicolumn{2}{|c|}{$35.52 \pm 4.47$} & \multicolumn{2}{|c|}{$32.25 \pm 3.44$} \\
\hline
\end{tabular}

The present study mean values for mid - clavicular circumference of clavicle as shown in table 5, was found to be lesser than that reported by various authors from different parts of India. This can be attributed to the fact of lesser intake of calcium in the form of milk and milk products by the East Indian population and this may have led to decreased thickness of the bone and hence lesser midclavicular circumference.

Table 6: Comparison of acromial length of clavicle as reported by various authors

\begin{tabular}{|c|c|c|c|c|}
\hline Authors & \multicolumn{2}{|c|}{ Right (in mm) } & \multicolumn{2}{c|}{ Left (in mm) } \\
\hline & Males & Females & Males & Females \\
\hline Sehrawat \& Pathak (North India) & $143.6 \pm 8.68$ & $131.17 \pm 7.75$ & $147.0 \pm 9.01$ & $134.19 \pm 7.81$ \\
\hline Present study & \multicolumn{2}{|c|}{$144.7 \pm 16.45$} & \multicolumn{2}{|c|}{$148.98 \pm 13.99$} \\
\hline
\end{tabular}

As shown in table 6, literature regarding the acromial length of clavicle is scarce. So, comparing the present study value to the literature available reveals that they are in congruence to the values of North Indian population.

\section{Conclusions}

From this comparative study we can conclude that:

1. Factors such as mechanical load, pressure and tension created by muscular attachments, and genetic endowments might be responsible for such asymmetries not only in various metric traits of clavicle but also among the non-metric traits of both side human clavicles.

2. The fact of lesser intake of calcium in the form of milk and milk products by the East Indian population and this may have led to decreased thickness of the bone and hence lesser midclavicular circumference.

3. Knowledge of clavicular length and its curvature is required for fixing external plates, whereas the diameter and width are needed for planning inter-medullary nailing for fixation of clavicular fractures. Fracture fixation plates need be anatomically contoured and locked.

\section{References}

1. Stranding S. Gray's anatomy. Churchill Livingstone, Elsevier Limited, London, 2009.

2. Sehrawat JS, Pathak RK, Variability in anatomical features of human clavicle: Its forensic anthropological and clinical significance, Translational research in anatomy: 2016; 3:5-14.

3. Kaur K, Rathee SK. Study of the Clavicular Curvatures in North-Indian Population, IJSR. 2017; 6(3):180-182.

4. McCormick WF, Stewart JH, Green H. Sexing of human clavicles using length and circumference measurements, Am. J Forensic Med. Pathol. 1991; 12:175-81.
5. Papaioannou VA, Kranioti EF, Joveneaux P, Nathena D, Michalodimitrakis M. Sexual dimorphism of the scapula and the clavicle in a contemporary Greek population: applications in forensic identification. Forensic Science International. 2012; 217(1-3):231-1.

6. Parsons FG. On the proportions and characteristics of the modern English clavicle, Journal of Anatomy. 1961; 51:71-93.

7. Mays S, Steele J, Ford M. Directional asymmetry in the human clavicle. International Journal of Osteoarchaeology. 1999; 9(1):18-28.

8. Andermahr J, Jubel A, Elsner A, Johann J, Prokop A, Rehm KE et al. Anatomy of the clavicle and the intramedullary nailing of midclavicular fractures. Clinical Anatomy: The Official Journal of the American Association of Clinical Anatomists and the British Association of Clinical Anatomists. 2007; 20(1):48-56.

9. King PR, Scheepers S, Ikram A. Anatomy of the clavicle and its medullary canal: a computed tomography study. European Journal of Orthopaedic Surgery \& Traumatology. 2014; 24(1):37-42.

10. Cunningham BP, McLaren A, Richardson M, McLemore R. Clavicular length: the assumption of symmetry. Orthopedics. 2013; 36(3):343-7.

11. Singh S, Jit I, Singh SP, Gangrade KC. Identification of sex from the skeletal remains. Bull Inst of Med Sci BHU. 1972; 3:65-75.

12. Terry RJ. The clavicle of the American Negro. Physical anthropology, 1932.

13. Olivier G. Anthropologie de la clavicule. III, la clavicule due francis. Bull et. Mem de la soc. D’Anthropologie. 1951; 2:121-57.

14. Patel JP, Shah RK, Merchant SP, Nirvan AB, Shah GV. Sexing of the human adult clavicle in Gujarat zone. Guj Med J. 2009; 64:40-6.

15. Sayee R, Janakiram S, Rajangam RK, Thomas IM. Clavicle- A metrical study. J of Ind Acad of Foren Sci. 1992; 3(2):24-9. 